Best practices in New Zealand career education and guidance

Best practices in career education and development in New Zealand secondary schools Manuscript to be published in the Australian Journal of Career Development in 2013.

\author{
Dale Furbish \\ AUT University of Technology \\ Lynette Reid \\ Auckland University of Technology
}

Dale Furbish and Lynette Reid are Senior Lecturers in the Graduate Diploma of Career Development at AUT University. Correspondence about this article should be sent to Dale Furbish, AUT University of Technology, School of Education, Auckland NEW ZEALAND dale.furbish@aut.ac.nz, +6499219999 


\title{
Best practices in career education and development in New Zealand secondary schools
}

\begin{abstract}
This study investigated best practices in New Zealand secondary school career education and guidance programmes. Schools considered to use best practices were identified by nominations from professional associations and from Careers New Zealand. A total of 20 nominated schools agreed to be included in the study and the career advisers of these schools were interviewed. Seven themes emerged from the interviews. These themes suggest career education and guidance programmes that are worthy of emulation by other schools, but the need to consider unique school and community characteristics in the design and implementation of career education and guidance is essential.
\end{abstract}

Career education and guidance are embedded in the education systems of many countries. A number of countries have developed guidelines and resources that are used by secondary schools to deliver career programmes. For example, the Australian government has adopted the Australian Blueprint for Career Development (MCEECDYA, 2010). The Blueprint identifies eleven career management competencies and provides a framework for designing, implementing and evaluating career development interventions directed to young people and adults. More broadly, the OECD (2004) has identified the contribution of career guidance and reviewed public policy of its members with regard to career guidance services. At the non-governmental level, professional associations such as the American School Counselor Association (ASCA; 2005) have also developed detailed models for career development programmes. A number of international investigations of best practices in school career education and guidance have been conducted (Curyer, 2011; Garza \& Clark, 1997; Maddy-Bernstein, 1997; Richard, 2005)

Yet such documents often only broadly identify the goals for career guidance and education or sketch the program activities that could be used to achieve the goals. Often absent is a discussion of the in-the-field practices used by career counsellors who are recognised by their peers for engaging in exemplary career practices. For example, Careers 
Best practices in New Zealand career education and guidance

New Zealand (2011) has recently developed career education benchmarks that provide a selfreview tool for gauging career development services in secondary schools. These benchmarks were developed from review of the international literature and in consultation with the New Zealand career development sector. Yet, the benchmarks are intended to provide aspirational goals rather than provide specifics programme elements.

Career development in New Zealand secondary schools has been an important activity for many years. Winterbourne (1974) described early programmes and services as far back as the 1920 s to assist New Zealand students make and implement career plans. Yet, in early career programmes, career planning largely focused on assisting male students to enter apprenticeships or to continue their education from the primary level to the secondary level. Career guidance was certainly not universal. Female students and Māori were for the most part not the target of career services as they were not perceived as requiring assistance because of the limited options available to them. However, career guidance and education programmes have evolved in New Zealand and are now widely found within New Zealand educational institutions (Furbish, 2012).

Career education and guidance has become recognised as an important programme in New Zealand schools for all students. The Ministry of Education (MOE; 2009a) stated that “all schools can make career education and guidance an integral and essential part of the education they provide” (p.4). Moreover, career education and guidance were recognised as a vehicle for better engaging students in learning as they think and prepare for their future.

Career education and guidance have been mandated by MOE for all New Zealand secondary students through the National Administration Guidelines (NAG). Specifically, NAG $1 f$ requires each school board of trustees, through the principal and staff to 
Best practices in New Zealand career education and guidance

provide appropriate career education and guidance for all students in year 7 and above, with a particular emphasis on specific career guidance for those students who have been identified by the school as being at risk of leaving school unprepared for the transition to the workplace or further education/training. (MOE, 2012)

While NAG $1 \mathrm{f}$ identified the centrality of career education and guidance programmes in school, few specifics were provided to give direction or content for these programmes. An attempt to provide structure to school career education and guidance programmes was initiated in 2005 through the Designing Careers programme. Designing Careers was a pilot programme developed by Career Services (now Careers New Zealand), the Crown Entity responsible for supporting career programmes in schools. Designing Careers targeted 75 schools and was run over 18 months. Hodgetts (2009) stated the goals for Designing Careers as:

Professional development support and teaching resources to teachers

Leaning and career planning for year 10 students

Individual career guidance for students at risk in years 11, 12 and 13 (delivered directly to students by Career Services consultants) (p. 11)

While a number of positive outcomes resulted from Designing Careers, the programme was of limited duration and also limited to only the targeted schools. Moreover, the structure and delivery of the programme was directed by an external agency and not from within the schools themselves.

A second school career education and guidance imitative occurred in 2007 to 2008. Again, Career Services was the developer and deliverer of this project, entitled Creating Pathways and Building Lives (CPaBL). CPaBL targeted 100 schools with the overarching goal of developing whole-school approaches to career programmes. The four goals of CPaBL were to 1) Share career knowledge and skills with all school staff and to assist in the development of career education policy for students with specific needs (i.e., Māori, Pasifika, 
Best practices in New Zealand career education and guidance

refugees and migrants), 2) Develop leadership within the school for planning and delivering career programmes and resources, 3) Develop planned approaches to career education and guidance that are sustainable and outcome focused, and 4) Engage parents, family and wider community in career education and guidance strategies (Career Services, 2007; as cited in Hodgetts, 2009).

Positive outcomes for school career programmes were reported (Education Review Office, 2009; as cited in Hodgetts, 2009). But, again, CPaBL was of finite duration and availability to selected schools. Further, the success of school-wide integration and sustainability of elements from CPaBL were called into doubt by the Education Review Office (ERO) report. Once CPaBL concluded, schools were individually responsible for the continuing the structure and form of career education and guidance.

Schools are given flexibility by MOE for designing and conducting career guidance and education as long the programmes address NAG $1 f$. Although MOE has published guidelines in this area, career education and guidance are not a specific part of the New Zealand curriculum. MOE (2007) connects student competencies of developing self awareness, exploring opportunities, and deciding and acting to career guidance and education, but only general guidelines are provided in relation to these goals. As a result, a variety of approaches and programmes have developed in schools to deliver career guidance and education.

MOE (2009) suggested a number of factors that support effective career education and guidance in schools. Among these are active leadership in career education and guidance by principals and senior management, a vision for career education and guidance from boards of trustees, monitoring evaluation and review of career education and guidance, a wholeschool approach, coordinated career education and guidance programmes with STAR (tertiary study) and Gateway (work experience) programmes, linking career education and 
guidance in pedagogy, personalisation of career education and guidance for students' needs, addressing the career education and guidance needs of target groups such as Māori, Pasifika, migrants and refugees, involving family, whānau, and community, sharing ideas about career education and guidance with other schools and providing for the professional development needs of those involved in career education and guidance.

A review of career education and guidance in New Zealand schools by the Education Review Office (2006) concluded the only 12 percent of secondary schools provide high quality career education and guidance to their students. Clearly, there is need for schools to do a better job in their career education and guidance programmes. One strategy for improving career programmes is to identify what is working well in the schools that are recognised as delivering high quality career services; that is to identify and disseminate information about best practices. Identifying best practices is an especially salient strategy for not only validating the effectiveness of practice within a given career education and guidance programme, but it leads to a mechanism for disseminating information about what works so that other schools can consider the suitability and potential for implementing similar career education and guidance practices in their settings. Identifying exemplary practice is a common approach for documenting effectiveness in New Zealand school curriculum areas and in school management (Aitken \& Sinnema, 2008; Alton-Lee, 2003; Anthony \& Walshaw, 2007; Robinson, Hohepa \& Lloyd, 2009).

The need to identify and disseminate best practices is further highlighted by research on New Zealand school career advisers. Vaughan and Gardiner (2007) found that a large number of New Zealand career advisers were relatively inexperienced in the role. Further, only 15 percent of career advisers hold a careers-related qualification. Almost two thirds were over the age of 50. Irving \& Cook (2011) noted that many career advisers were entered into the role with no knowledge or background in career. Often, career advisers are "shoulder tapped” for 
Best practices in New Zealand career education and guidance

the role by the school principal or fell into the role by chance rather than making conscious choices about entering the role. Assisting New Zealand career advisers identify what works best in other school career education and guidance programmes therefore provides practices and models that may be emulated in many settings.

Other attempts to identify the elements of quality career education and guidance in New Zealand schools have been recently conducted. The Education Review Office (2012) studied 44 secondary school career programmes, identifying four as having whole-school high quality programmes, 17 having “conventional established” programmes, 19 as having “conventional developing” programmes and 4 having low quality programmes. Similar to the findings of the current research, those schools whose career programmes were judged to be high quality enjoyed support from the school leadership and management, employed systematic initiatives across the years, had developed targeted activities for at risk students, established good relationships with the community, undertook periodic self-reviews and employed career advisers with specific career expertise and training gained from formal qualifications in career or extensive professional development.

\section{Method}

\section{Participants}

In order to identify best career education and guidance programmes, requests for nominations of schools that were acknowledged to have quality career education and guidance programmes were sent to the Presidents of Career Development Association of New Zealand (CDANZ) and Career and Transition Educators Aotearoa (CATE), and to the National Director of Careers New Zealand, who coordinates services for secondary schools. CDANZ is a professional association for career practitioners and membership includes secondary career advisers. CATE is an organisation for secondary school career staff. Careers New Zealand 
Best practices in New Zealand career education and guidance

provides services and resources to secondary schools career education and guidance programmes and works closely with schools across New Zealand.

The request for nominations sought the identification of schools whose career education and guidance programmes were recognised as being exemplary and having a good reputation among peers. Although no limitations were included, the request asked for a range of characteristics (such as size of student enrolment rolls, government and private governance, urban and rural settings, North and South Islands location, and a range of socio-economic classifications) to be considered when making nominations. A total of 32 schools were nominated from the combined sources.

\section{Procedure}

The career adviser from each nominated school was contacted by e-mail with a follow up telephone contact to explain the research. Of the nominated schools, 20 agreed to participate. The consenting schools represented the desired range of characteristics. The consenting schools' career advisers were also sent a project information sheet, consent forms for the individual career adviser and for the principal, and a list of indicative questions to be used.

Each of the participating schools was visited by one of the research project staff. During the visit, the career adviser was interviewed using a standard set of open-ended questions. The interviews were audio recorded and notes were taken. The questions sought to obtain descriptions of each school's career education and guidance programme, resources, and specific activities. Of interest also was the overarching programme philosophy. Information was sought about interfaces between the career education and guidance programmes and significant stakeholders such as school management, teachers, boards of trustees, employers 
Best practices in New Zealand career education and guidance

and community resources. Descriptions of career education and guidance activities that addressed the needs of Māori, Pasifika and immigrant student were also requested.

\section{Results}

Upon completion of all interviews, the audio recordings and written notes were reviewed. A number of themes that distinguished exemplary career education and guidance practices in the schools were identified.

\section{Theme One: Career Adviser Characteristics}

The first theme that emerged was the characteristics of the career adviser. In all instances, the career adviser’s enthusiasm, dedication and knowledge were fundamental for exemplary practice. Most of the career advisers had been in the role for more than 5 years. They reported that they wanted to be in the career adviser role and identified with the programmes and activities. While the influence of Careers New Zealand initiatives Designing Careers and $\mathrm{CPaBL}$ were recognizable, the career advisers had embellished and extended the structures and activities of those programmes. The source for knowledge about career initiatives came from involvement in professional development through CATE and in a number of instances formal qualifications in career development. A common characteristic found among the career advisers was their ability to establish professional networks with career advisers in other schools. These networks often resulted in exchanges of information about career programme approaches. Frequently, career advisers noted that a particular career education and guidance strategy or resource was first used by a colleague at another school. In one instance during the data gathering, career advisers from four schools met as a group to be interviewed. It was observed that even during this group interview, each career adviser took notes and asked questions about the career education and guidance practices that were being described. 
Best practices in New Zealand career education and guidance

Another person characteristic evident from the interviews with the career advisers was their "marketing" skills. The career advisers described their efforts to promote the merits of career education and guidance programmes to school management, teachers, parents, employers and boards of trustees. While the goals of career education and guidance programmes are generally attractive to school stakeholders, the career advisers reported that they frequently obtained specific resources, support and co-operation from stakeholders as a result of their advocating for the career education and guidance programme.

The characteristic of advocacy was also notable when career advisers described their personal involvement when responding to the career needs of individual students. For example, when career advisers discussed the specific qualities of a student with tertiary recruiters or employers more personalised strategies emerged.

Career advisers attributed their influence and credibility when promoting career education and guidance to their experience as teachers and in a number of instances to other school management roles such as deans. Yet, it was acknowledged that dual teacher/career adviser roles could send a mixed message to students. Students tended to relate to career advisers in their role of teacher as an expert who could provide definitive answers to questions. However, the career advisers acknowledged that when in the role of career adviser, they encouraged students to not look to them as sources of quick answers to career development issues. The career advisers appeared to successfully straddle the roles of teacher/career development specialist with the conflicting expectations of students.

\section{Theme Two: School Characteristics}

A second theme identified in the data related to school characteristics. Although there was variation among the schools (location, size, socio-economic characteristics), each school that was nominated as possessing an exemplary career education and guidance translated its 
Best practices in New Zealand career education and guidance

demographic characteristics to advantageously support its career programme. For example, larger schools often had more resources and career staff than the smaller schools. The larger schools thus developed more career development strategies and activities, whereas the smaller schools capitalised on one-to-one career adviser-to-student interactions. Resources varied among the schools for student information systems. Some schools possessed student information systems that allowed for teachers as well as career development staff to input comments about students’ career plans. Less broad based information systems utilised detailed input from only career advisers to record students’ career development and related activities. Yet all the schools shared a priority for career development reflected by the central and accessible physical location for career rooms and career staff.

\section{Theme Three: Use of Developmental Strategies}

A third theme emerged from the developmental strategies employed in the career education and guidance programmes. In all the nominated schools, sequential goals and activities appropriate for students of different ages drove the career programme targeting students is each academic year. Typically, students in Years 9 and 10 were exposed to exploratory notions of career. In one of the smaller schools, the career adviser led a camp experience for Year 9 students at the beginning of the school year. He believed that such an experience created a bond between him and the students that was invaluable as the students moved through their secondary school education and developed career plans.

Students in Years 11 and 12 received more specific occupational and educational information, and also were provided with activities designed to assist them with career decision-making and career management skills. Participation in career related programmes such as Gateway (which provides work experience) and STAR (which funds secondary school students' enrolment in tertiary courses) is offered to Years 10 and 11 students. Often career 
Best practices in New Zealand career education and guidance

activities for Year 13 students centre on visits to polytechs (TAFE) and universities and other tertiary training organisations.

The influence of Careers NZ materials and programmes (e.g. CPaBL) was evident in the differential programmes for students in each year of study. While the developmental nature of career is reflected in the activities, career advisers did not identify concepts from developmental career theory (e.g. Super, Super, \& Savickas, 1996). Yet they seemed to recognise that career development is not a function of chronological age but of career maturity (the capacity to form a vocational self concept based on the synthesis of self-knowledge and environmental knowledge).

\section{Theme Four: Whole School Approach}

A fourth theme is a whole school approach to career education and guidance. The Careers NZ CPaBL programme was again influential for providing a philosophy and activities as a number of nominated schools had participated in the CPaBL. A central feature of CPaBL was to involve subject area teachers in career education and guidance through their teaching and classroom activities. In many of the schools that participated in the current research, the career adviser served as a resource and support to classroom teachers. Specific activities included conducting professional development sessions for class room teachers about career education activities appropriate for classroom delivery and actually collaborating with classroom teachers to deliver career education topics.

As noted above, New Zealand schools receive funding for two career related programmes, Gateway (work experience) and STAR (tertiary enrolment). The coordination of these programmes with the overall career education and guidance initiatives was apparent in schools that were identified in the current study. In many cases, Gateway and STAR staff are located in the same physical area as the career adviser. This arrangement fosters a natural 
Best practices in New Zealand career education and guidance

relationship and collaboration among the staff who work in these programmes. A coordinated strategy among the various elements of career education and guidance programmes seems to maximise resources, resulting in effective career practice.

\section{Theme Five: Support from Boards of Trustees and Senior Management}

Support for career education and guidance from the school's Board of Trustees and senior management was a fifth theme. The Principal is responsible for meeting the National Administration Guidelines such as NAG $1 f$ that mandates career education and guidance. Leadership from Boards of Trustees and Principals was evident in the schools that were nominated as providing exemplary career education and guidance. Although the career adviser often was assigned the specific responsibility for career programmes, the support of the Board of Trustees and the Principal was obvious and essential. Support was reflected in allocation of school resources and budget for the career programmes. Further support was in evidence from specific direction to classroom teachers to develop and deliver career education. In each instance, the career adviser who was interviewed stated that a robust career education and guidance programme would not be possible without the overt support of Boards of Trustees and Principals.

\section{Theme Six: Use of School and Community Appropriate Strategies}

A range of specific programme elements was represented in schools that participated in this study. However, a sixth theme that was noted had to do with the delivery of activities and services that were appropriate for the individual school's culture and the school's community. While some activities such as career newsletters and trips to visit polytechs (TAFE), universities and other tertiary education providers were universal, there were individual initiatives that reflected the specific environment and needs of the school. For example, there were structures for permitting career advisers to interact with students through house groups 
that varied according to the administrative organisation of the school. The use of social media such as Facebook to interact with and inform students varied as a function of the knowledge and interest of the career advisers. Meetings with parents, especially those of Māori, Pasifika and immigrant students, were frequently used by career advisers to engage parents in students’ career development and also to inform parents about career issues for their children. However, the specific format of the meetings varied according to size of the school and size of the community. Contact between career advisers and employers also varied as a function of time and community context. Nonetheless, the strategies that were used made sense for the school and community environments.

\section{Theme Seven: On-going Review}

A seventh theme was the periodic and regular review of the career programmes and modifications made as a result. Reviews occurred often were required by school management as part annual reporting. However, the reviews were characteristically viewed as useful by the career advisers and modifications to career education and guidance programmes were likely when deficiencies or opportunities for innovation were identified.

\section{Discussion}

The information collected about the career guidance and education programmes in New Zealand secondary schools suggested that comprehensive and high quality programmes exist. Not surprisingly, there was variation in the programme specifics based on size of the school, geographic location and resources. However, a constant across all the programmes was the enthusiasm and dedication of the career adviser. Some of the career advisers were relatively new to the career adviser role, while others had been serving in that role for a number of years. Regardless, a strong theme that emerged during the interviews was the ownership and pride in the career programmes and recognising the value of the programmes 
Best practices in New Zealand career education and guidance

to student career decision making.

Also apparent was the overlap between the structure and practices of the career programmes with the New Zealand Ministry of Education’s (2009) guidelines for effective career education practices. This document identifies a number of key elements that appeared in the programmes that were studied.

An element that appears in both the MOE guidelines and the programmes investigated was the importance of leadership. The programmes that were nominated as best practice all seemed to enjoy the support of the school principal and the senior leadership of the school. In many instances, school support for the career education and guidance programme was augmented by the role of the career adviser in the school's senior management. The school leadership role, however, was not always a function of being the career adviser, but frequently emerged from other roles. In a number of instances, the career adviser was also a year dean. The dean's role provided inclusion on the school's management team rather than the career adviser's role. While such an arrangement benefitted career programming by providing a voice and influence in the school management, clearer recognition of the centrality of career guidance and education would be gained by the including the career adviser on the school management team as a function of the career portfolio itself rather than only from other roles and responsibilities.

A team approach to career education and guidance was another characteristic found in many of the programmes and suggested by the MOE guidelines. In most cases, a team approach was forged between classroom teachers and the career advisers, thereby also conforming to MOE advice to incorporate the school curriculum into career programmes. In some cases, this approach was implemented by the career adviser teaching a unit related to careers in various subject areas. However, there were some instances when the class room 
Best practices in New Zealand career education and guidance

teacher would the deliver career related topics with the assistance of the career adviser. Integrating career topics into ongoing classroom instruction would seem to be most desirable, as career topics are more likely to be seen by students as natural progressions of academic content rather than add-on topics. On-going integration of career topics into subject content delivery also has the advantage as it removes the perception by teachers that delivering career topics takes time away from class time needed to cover content needed for the National Certificate of Educational Achievement (NCEA). While partnerships between career advisers and classroom teachers are desirable, Schloss (2011) has noted the desirability of professional development about career development directed to classroom teachers. Her study of Australian secondary school teachers concluded that despite good intentions, classroom teachers often did not have understanding of career theories and concepts needed to most effectively integrate career topics into academic materials. Such conclusions suggest that professional development about career is important for all school personal.

MOE guidelines that call for a co-ordinated approach to career education and guidance seem to make sense. Effective career programmes were found to rely on coordination between career advisers and administrators of other career initiatives such as Gateway (work experience) and STAR (concurrent tertiary study). Often the school career office and the Gateway and STAR offices were located together, thereby facilitating the synchronization of the activities and staffing from the three career related programmes.

Professional development for career advisers is called for in MOE guidelines. While a number of the career advisers interviewed in this research had completed a formal qualification in career development, formal qualifications in a career specific academic programme were not universal. Those career advisers who had completed a formal qualification in career development generally developed programmes and practices that were utilised career development theory, creating theory-supported approaches to career 
Best practices in New Zealand career education and guidance

development. Those career advisers who were interviewed but who did not possess an academic qualification in career development were able to still develop what were considered best practice services. However, the absence of formal qualifications potentially limited the refinement of their practice based on theory and research that they had not been exposed to. Just as teachers are required to possess suitable qualifications to be registered and practice as a teacher, a parallel argument is that career advisers and career development and guidance programmes would benefit from formal study in the career development disciplines.

Involvement of family, whānau and the community, as suggested by MOE, were characteristic of the career guidance and education programmes studied. Such involvement, however, appeared to be more extensive and more fundamental to the programmes in smaller and more rural school career programmes. This is likely to a possible greater sense of community in smaller schools and also possibly owing to the more likely social interactions between career advisers and the community members in smaller communities. Yet, there were also a number of examples from larger and urban schools based on recognising the value of interactions among school career personnel, students' families and whānau, local employers and local education providers.

This study has affirmed the existence of high quality career practices in New Zealand schools. These practices are worthy of emulation by New Zealand schools that do not possess as fully developed career education programmes and strategies. However, the range of approaches usually responded to localised communities and school environments. Career advisers seeking to employ best practices should be mindful of their own school, student and community contexts. 


\section{References}

Aitken, G., \& Sinnema, C. (2008). Effective pedagogy in social sciences/ tikanga à iwi: Best evidence synthesis iteration. Wellington, New Zealand: Ministry of Education

Alton-Lee, A. (2003). Quality teaching for diverse students in schooling: Best evidence synthesis iteration. Wellington, New Zealand: Ministry of Education.

American School Counselor Association (2004). ASCA national model: A framework for school counseling promrams (rev.). Alexandria, VA: Author.

Anthony, G., \& Walshaw, M. (2007). Effective pedagogy in mathematics/pàngarau: Best evidence synthesis iteration. Wellington, New Zealand: Ministry of Education.

Curyer, S. (2011). Schools Best Practice Showcase. Paper presented at the International Association for Educational and Vocational Guidance Conference, April 2011, Cairns, Australia.

Education Review Office. (2006). The quality of career education and guidance in schools. Wellington, New Zealand: ERO.

Education Review Office. (2012). Careers information, advice, guidance and education (CIAGE) in secondary schools. Wellington, New Zealand: ERO.

Furbish, D. (2102). An overview of New Zealand career development services Australian Journal of Career Development 21 (2), 14-24.

Garza, V. \& Clark, S. (1997). Exemplary career guidance and counselling. Retrieved from www2.ed.gov/offices/OVAE/tx3/html

Hodgetts. I. (2009). Rethinking career education in schools:

Foundations for a New Zealand framework. Wellington, New Zealand: Career Services

Irving, B. A. \& Cook, J. (2011). Choice, chance or compulsion: The recruitment of career advisers into New Zealand secondary schools. REOP 22 (2), 109-119.

Maddy-Bernstein, C. (1997). Exemplary career development programs: Learning from the best. Retrieved from http://vocserv.berkely.edu/CW821/exemplary career.html 
$\underline{\text { www.blueprint.edu.au }}$

Ministry of Education. (2007). New Zealand Curriculum. Retrieved from (http://nzcurriculum.tki.org.nz/Curriculum-documents/The-New-Zealand-Curriculum

Ministry of Education. (2009). Career education and guidance in New Zealand schools. Wellington, New Zealand: Career Services.

Ministry of Education. (2012). National Administration Guidelines. Retrieved from http://www.minedu.govt.nz/theMinistry/EducationInNewZealand/EducationLegislatio n/TheNationalAdministrationGuidelinesNAGs.aspx\#NAG1

OECD (2004). Career guidance and public policy: Bridging the gap. Paris, France: OECD.

Richard, G. (2005). International best practices in career development: Review of the Literature. International Journal for Educational and Vocational Guidance 189-201 DOI 10.1007/s10775-005-8799-9

Robinson, V., Hohepa, M., \& Lloyd, C. (2009). School leadership and student outcomes: Identifying what works and why. Wellington, New Zealand: Ministry of Education.

Schloss, J. (2011). Career development in schools: Do teachers have the skills? Australian Journal of Career Development 20 (3) 4-9.

Super, D., Super, C., \& Savickas, M. (1996). A life-span, life space approach to careers. In D. Brown, L. Brooks, \& Assocaites, Career choices and development ( $3^{\text {rd }}$ ed.), (pp 121178). San Francisco, CA: Jossey-Bass.

Vaughan, K. and Gardiner, B. (2007). Career education in New Zealand schools. Wellington, New Zealand: NZCER.

Winterbourne. R. (1974). Guidance services in New Zealand education. Wellington, New Zealand: NZCER 